\title{
Critical success factors for improving learning management systems diffusion in KSA HEls: An ISM approach
}

\author{
Yousef Alduraywish $^{1} \cdot$ John Patsavellas ${ }^{1} \cdot$ Konstantinos Salonitis $^{1}$ (D
}

Received: 30 December 2020 / Accepted: 6 June 2021 / Published online: 7 July 2021

(c) The Author(s) 2021

\begin{abstract}
Higher educational institutes (HEIs) are managing their resources by using learning management systems (LMS) which facilitate the learning processes. This paper aims to develop the relationships among success factors typically found in the technology, as well as the human and organisational aspects using an interpretive structural modelling (ISM) approach for LMS diffusion in HEIs in the Kingdom of Saudi Arabia (KSA). The success factors possessing a higher driving power in the ISM approach need to be prioritised as many other dependent variables are affected by them. Success factors emerging with high dependence contribute to facilitating the implementation of LMS. A key finding of the modelling is that clearly defined information technology (IT) policies along with appropriate technology infrastructure are significant factors for facilitating the technology aspect of LMS implementation. Additionally, the strengthening and standardisation of IT education resources, level of computer skills, proper training programmes for staff to deliver knowledge to users as well as a high level of human competencies are significant factors for facilitating the human aspect of LMS implementation. Moreover, the support of top management is a very significant factor for improving the organisational aspect of LMS. To ensure successful LMS implementation, KSA HEIs should focus on effective learning environments, facilitate education activities, top management involvement and increased interaction between pedagogy and technology. Understanding user characteristics and online needs is essential to ensure that barriers are overcome, ensuring successful and continued LMS implementation. Further, in this research, the relationship models among the identified success factors in terms of technology, human and organisational have not been statistically validated. However, it has been suggested that future research may be targeted to develop the initial model through ISM for success factors for improving LMS implementation and then testing it using Structural equation modeling (SEM).
\end{abstract}

Keywords Learning management systems · LMS · Interpretive structural modelling $\cdot$ ISM $\cdot$ Success factors

Extended author information available on the last page of the article 


\section{Introduction}

Higher educational institutes (HEIs) seek to provide suitable educational environments within the framework of each country's education policies to achieve highquality education outcomes, raise research efficacy, support innovation and creativity, and to develop students' skills and capabilities (Pyla, 2012). As a result, HEIs implement information systems (IS) to manage all learning functions which are collectively referred to as Learning Management System (LMS) (Del Giudice et al., 2014).

LMS is the backbone for online learning and is managing the learning processes, classrooms, tests, and assignments (Radif, 2016). The role of LMS in educational environments has been studied by Jamal and Shanaah (2011). Their research concluded that its use facilitates learning activities as well as helps learners to learn from their peers. LMS utilise data and communication technology to develop creative approaches to learning. Further, numerous educational processes are supported such systems; which is a full-scale learning platform (Kats, 2013).

Alebaikan and Troudi (2010) pointed out the capacity of universities in KSA is limited compared with the rapid growth of students applying for higher education; which is considered significant challenges that HEIs in KSA face. Therefore, The Saudi Ministry of Education has supported the use of IT for education activities among instructors and learners. According to Al-Fahad (2010), KSA has announced officially the application of e-learning and distance learning, and to achieve these goals, leading towards the future has launched initiatives to establish infrastructure for higher education and e-learning education. However, most of the courses in HEIs are primarily taught in the classroom.

This paper aims to identify and rank the key success factors for improving LMS diffusion in KSA HEIs, to establish the relationships among the identified success factors using the interpretive structural modelling (ISM) approach and to discuss the implications for practicing managers of this research and suggest directions for future research. These success factors affect one another. Therefore, it is essential to recognise the nature of these factors so that the driving factors and dependent factors are recognised.

Following the introduction section is the literature review of success factors that affecting LMS diffusion. Then, the ISM implementation in current research is presented, including ISM-based model and MICMAC analysis. Next, discussion section that cover technology implications, human implications and organisation implications for practicing managers. Finally, the paper ends with the conclusions.

\subsection{Identification of success factors}

The various success factors affecting LMS diffusion in KSA HEIs were identified from the following: 
- Extensive literature search was carried out using the following sources: Scopus, Science Direct and Google Scholar. The following keywords were used in the search: "learning management systems", "e-learning", "barriers factors for LMS adoption", "success factors for LMS adoption and technology acceptance among higher education". In the literature search, academic journals and online peer-reviewed journals were included, most of which were recent; however, a few articles published earlier were considered. A total of 35 papers are included from these sources.

- The researchers discussed success factors with a group of experts (four academics and six practitioners); who have enough knowledge about education technology, working in the higher education sector as well as their work experience is more than 7 years in the higher education sector.

Heeks (2003) argued that the success or failure of any information systems depends on the degree of mismatch between the conception and the reality into which it is introduced. The ITPOSMO model is a useful framework to identify the success factors and to study how leaders practically deal with them. Therefore, the success factors are grouped into three categories: ten factors as technology factors (information, technology, and process), seven factors as human factors (objectives and value, staff and skills), and seven factors as organisational factors (management structures and other resources) (Heeks, 2003). In the following paragraphs, these three categories will be discussed in more detail:

- Technology success factors: Proper technology infrastructure reflects facilitating conditions which make sure that the infrastructure is easily accessible and convenient. As a result, the LMS can be used effectively. In other words, presence of proper technology infrastructure helps both academics and students in terms of adopting the LMS successfully. Consequently, the presence of a robust IT infrastructure is integral in revealing the commitment to LMS, thereby stimulating the emergence of favourable conduct among learners and academics (Solangi et al., 2018). Availability of IT equipment that helps users perform academic activities is another technology success factors. As per findings of Basak et al. (2016), LMS can be implemented successfully in HEs by focusing on technological factors. Some of the key technological factors include hardware and software, and an ease of access to IT equipment. Access to IT equipment facilitates adoption of LMS, which in turn strengthens the development of online learning within HEIs. Clear policies for LMS implementation is crucial for effective implementation of the LMS because it governs how LMS can be developed, used, managed and administered. LMS policy further helps HEIs in adhering to Higher Education Standards Framework. It also guides the academic board in decision-making process related to LMS design and development based on the set budget (Iqbal \& Qureshi, 2011). Similarly, among the success factors under the technology, the presence of an Educational Process Reengineering enhances the performance across the dimensions of utility for LMS, including the learning and teaching activities, with additional benefits in administrative and education assessment. Generally, HEIs operate, maintain and manage educational administration 
by using technologies. Yet, lack of scientific approach requires more attention towards role of students, teachers and administration staff while integrating technology with learning. Therefore, EPR process helps HEIs in terms of enhancing the main teaching-learning processes via selection of suitable technologies (Khalid et al., 2011). Technical Support for the LMS operation is another technology success factor. This is so because effective use of LMS by users require support services. Otherwise, lack of technical support and training results into poor utilisation of key features of LMS. Resultantly, this leads to two outcomes. First of all, there would be no usage at all of LMS. Secondly, there could be limited usage of LMS based on its relatively few features only (Mtebe, 2015). LMS software that covers the university needs is considered as technology success factor. According to Kraleva et al. (2019), installation of LMS software is necessary for self-hosted LMS, which allows users to run and use LMS by either accessing to server of the HEIs or installing on their hard drives. Additionally, by integrating LMS with other technology-based systems, such as student information system, an institution is able to diversify the value of LMS. A study by Abu-shawar et al. (2006) showed that effectiveness of integration between LMS and information system of a HEIs is based on consistency of the data. It also revealed that this integration offers benefits in terms of reduced cost and time efforts, in addition to transforming manual services into automatic ones. Common examples include automatic creation of accounts, enrolment process, and grade distribution. The eighth technology success factor for an effective LMS implementation is a high-quality maintenance plan for LMS software and hardware. According to Oludele et al. (2014), maintenance costs are highly crucial in contrast to buying costs ofLMS. Therefore, desired performance of LMS can be attained by regularly performing both testing and maintenance procedures of LMS. This eventually results into minimal occurrence of sudden system failures. Complete E-courses portfolio is one of the technology success factors. According to Queirós et al. (2011), an effective integration of LMS with specialised e-portfolio system offers a positive learning experience to students within an educational setting. The rationale for integration of LMS with e-portfolio system is that it allows the user to employ e-portfolio as an assessment tool. The last technology success factor for an effective LMS implementation is information accuracy. According to Ohliati and Abbas (2019), quality of information provided by LMS is measured through its timeliness, relevancy, accuracy, consistency and completeness. For example, accuracy is an output feature of LMS that defines quality of information (Table 1).

Human success factors The first human success factor for an effective LMS implementation is comprehensive vision to focus on educational goals. It is a crucial component that exists within the planning stage of LMS. Based on the findings from the study by Al-Fraihat et al. (2017), the implementation of LMS is only effective if there is an articulate goal, vision and measurable objectives that are relevant to online systems for teaching purposes. Yet, it must be noted that the study of current 


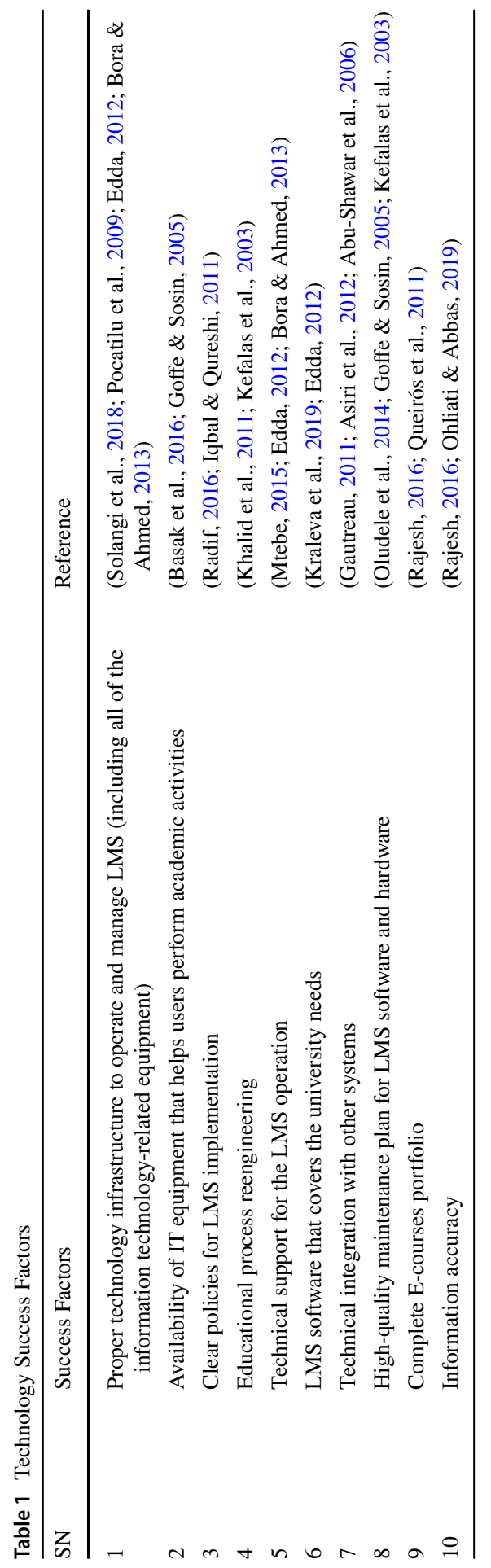


online learning context of HEIs is necessary for a clear identification of LMS purpose, vision and goals. Clear implementation of the educational processes through LMS is another human success factors. This is so because when right people are trained for gaining right knowledge or skills at the right time, then educational processes can be implemented clearly, thereby leading to a reasonable LMS. In other words, academics productivity reflects better implementation, which in turn leads to better adherence to educational principles of LMS (Govindasamy, 2001). In addition to it, strengthening and standardisation of IT education resources is important human success factors. This is so because when strong and customised online IT resources are offered, then this leads to better academic performance through LMS. Alternatively, the successful implementation of LMS is dependent on the internal resources and expertise, oversight over administration of the existing systems, and any measures for continuous improvement into the future (Turnbull et al., 2019). The fourth human success factor for an effective LMS implementation is strong knowledge of LMS aspects to proactively provide support for learning initiatives and motivate learners. This reflects that quality of instructor or teacher plays a crucial role in affecting learners' behaviour by sharping their behaviour during the online course, and thus, applying LMS effectively. Instructors can offer support to learners through tehri teaching style, strong knowledge, response timeliness, and assistance during the online learning process (Lwoga, 2014). The fifth human success factor for an effective LMS implementation is IT staff with high level of computer skills. It means that support and computer skills of the IT staff leads to better service quality, and thus, effective LMS application. IT staff can deliver exceptional and effective computer skills by being responsive and available whilst delivering technical assistance and exercising their computer skills. In this way, high computer skills will lead to better online learning system, and thus, predict high learner satisfaction with LMS (Lwoga, 2014). Moreover, proper training programs is necessary to improve staff skills. According to Solangi et al. (2018), proper training programs shows a strong profile of users. A trained user will be confident and show positive attitude while accessing technology. Therefore, provision of proper training programs to users enhance their experience and technical efficacy during conduction of online courses, using internet in the learning process, administrating the course, and thus, using LMS. The last human success factor for an effective LMS implementation is high level of human competencies. As per findings of Solangi et al. (2018), LMS can be implemented successfully based on performance of instructors. Self-efficacy of instructors shows their learning efficiency and competency. When are self-confident and use interactive pedagogies while performing, then this results into innovative outcomes of LMS. Besides it, the success factor also reflects technology competency of students. It means that when students have firm belief on their capability and ability of using online learning technologies, then this results into effective LMS implementation during the learning process (Ayub et al., 2010) (Table 2).

Organisational success factors The first organisational success factor for an effective LMS implementation is top management support. According to Basak et al. (2016), support from the top management is very crucial during designing, planning, implementing, and monitoring LMS. Top management support also leads to enhanced 
Table 2 Human success factors

\begin{tabular}{lll}
\hline SN & Success Factors & Reference \\
\hline 1 & Comprehensive vision to focus on educational goals & (Al-Fraihat et al., 2017; Mayer, 2004) \\
2 & $\begin{array}{l}\text { Implementation of the educational processes through } \\
\text { LMS }\end{array}$ & (Govindasamy, 2001; Zampunieris, 2006) \\
3 & $\begin{array}{l}\text { Strengthening and standardisation of IT education } \\
\text { resources }\end{array}$ & (Turnbull et al., 2019) \\
4 & Knowledge of all aspects of the LMS & (Lwoga, 2014; Mtebe, 2015) \\
5 & IT staff with high level of computer skills & (Whelan \& Bhartu, 2007; Lwoga, 2014) \\
6 & Proper training programs & (Pyla, 2012; Solangi et al., 2018) \\
7 & High level of human competencies & (Gautreau, 2011; Ayub et al., 2010; \\
& & Solangi et al., 2018) \\
\hline
\end{tabular}

awareness and encouragement towards users relative to using the online learning/ teaching platform. Deep understanding of users' needs to facilitate education activities is another orgnisational success factors. As per findings of Phongphaew and Jiamsanguanwong (2018), common needs of users while using LMS include ease of use and a less complex system. When these needs are met, then users show satisfaction with LMS and adopts it successfully. A usability test is highly useful in this regard since it reflects users' needs, and thus, leads to high adoption rate of LMS through its easy design. In addition to it, academics support to produce digital content is another organisational success factors. According to Santiago et al. (2020), online campus offers support to academic so that they can better apply LMS. Common examples of teaching support include encouragement of teaching innovation, facilitation of student tracking, self-assessment, virtual forums, promoting communication among various users, self-learning, and provision of online teaching experiences with different extents of virtuality. The fourth organisational success factor for an effective LMS implementation is proper training program for users based on their needs. As per findings of Solangi et al. (2018), proper training programs shows a strong profile of teacher. A trained teacher will be confident and show positive attitude while accessing technology. Therefore, provision of proper training programs to teachers enhance their experience and technical efficacy during conduction of online courses, using internet in the learning process, administrating the course, and thus, using LMS. Moreover, encourage academics and students to using LMS is one of the organisationl success factors. According to Santiago et al. (2020), effectiveness of LMS is based on how far it engages learners, provides interesting learning, and allows them to seek self-development proactively. In other words, when learners are encouraged to take part in online learning through an easily accessible LMS, then it not only fulfils user needs, but also lead to successfully execution of LMS functions. The next organisational success factor for an effective LMS implementation is increase awareness level for academics and students. As per findings of Juhary (2014), learning through LMS among students can be improved if the top management believes in the learning management system. This in turn requires the top management to enhance awareness of LMS among students and academics for 
supporting learning activities among students. The last organisational success factor is increase knowledge sharing among LMS users. According to Iqbal and Qureshi (2011), high capability of interaction among users while using LMS results into its effective execution. For example, academics can share knowledge by posting key announcements in a specific area which is easily accessible by all students. Likewise, students can share their viewpoints with academics through the discussion board. In this way, knowledge sharing transforms the role of students from passive viewers to active participants. Besides these, knowledge sharing through wikies, live chat rooms and blogs also allows flexible communication among teachers and students, and thus, LMS leads to desired learning and teaching outcomes (Table 3).

\subsection{ISM implementation}

According to Attri et al. (2013), ISM 'is a well-established methodology for identifying relationships among specific items, which define a problem or an issue'. Based on these identified relationships, the overall structure is extracted ISM structure from the complex set of variables. It is intended as a group learning process; however, in some cases, ISM is used individually.

ISM Steps: The following steps involved in ISM methodology:

Structural self-interaction matrix (SSIM): For completing the SSIM, two experts with essential and valuable knowledge about the research theme and aims were identified (Jharkharia \& Shankar, 2005; Attri et al., 2013). The criteria for selecting these experts included academics who should have enough knowledge about education technology, working in the higher education sector as well as their work experience is more than 7 years in the higher education sector. After that, an email was sent to the experts explaining to them the aim of this study. At this point, the researchers arranged a meeting with experts to discuss the identified success factors. Then, they were consulted to assist in identifying the nature of contextual relationships among the success factors for improving LMS diffusion. To analyse the success factors in developing SSIM, the following four symbols have been used to denote the direction of the relationship between success factors ( $i$ and $j$ ).
$A$, if variable $i$ affects $j$.
$B$, if variable $j$ affects $i$.
$C$, if variable $i$ and $j$ affect each other.
$\mathrm{D}$, if there is no effect between each other.

Based on contextual relationships, the SSIM was developed for variables identified for the success factors in terms of technology (Table 4), the human (Table 5), and the organisational (Table 6) in LMS. 


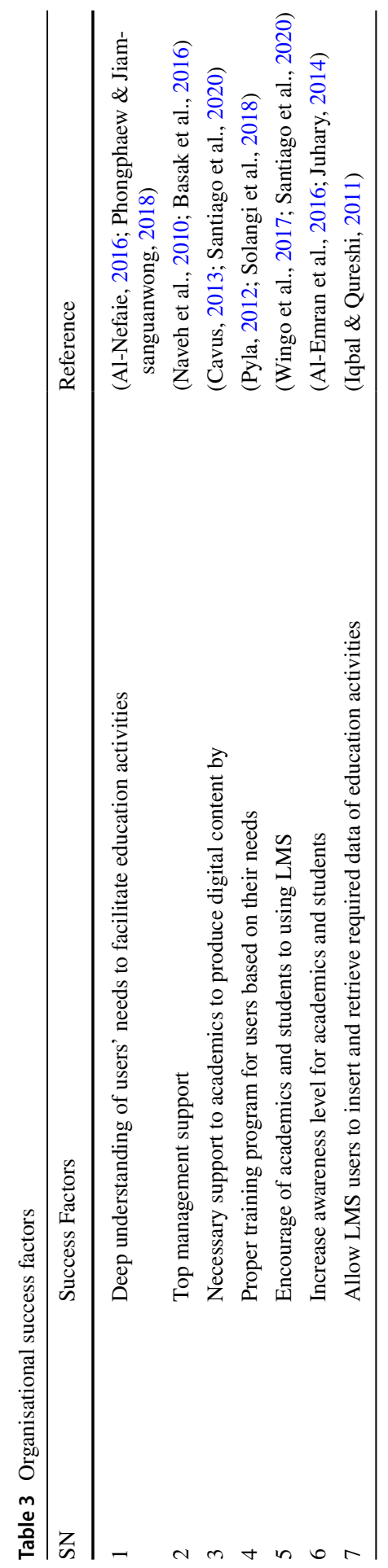


Table 4 SSIM for technology success factors

Table 5 SSIM for human success factors

Table 6 SSIM for organisational success factors

\begin{tabular}{llllllllll}
\hline $\begin{array}{l}\text { Success } \\
\text { Factors }\end{array}$ & 10 & 9 & 8 & 7 & 6 & 5 & 4 & 3 & 2 \\
\hline 1 & D & D & A & A & A & A & A & B & C \\
2 & D & D & A & B & B & B & B & B & \\
3 & A & A & A & D & A & A & A & & \\
4 & A & A & B & B & D & B & & & \\
5 & D & D & A & A & B & & & & \\
6 & A & A & A & B & & & & & \\
7 & A & D & A & & & & & & \\
8 & A & A & & & & & & & \\
9 & D & & & & & & & & \\
10 & & & & & & & & & \\
\hline
\end{tabular}

\begin{tabular}{lllllll}
\hline $\begin{array}{l}\text { Success } \\
\text { Factors }\end{array}$ & 7 & 6 & 5 & 4 & 3 & 2 \\
\hline 1 & B & B & B & B & C & A \\
2 & B & B & B & C & B & \\
3 & D & A & A & B & & \\
4 & B & A & B & & & \\
5 & C & C & & & & \\
6 & A & & & & & \\
7 & & & & & & \\
\hline
\end{tabular}

\begin{tabular}{lllllll}
\hline $\begin{array}{l}\text { Success } \\
\text { Factors }\end{array}$ & 7 & 6 & 5 & 4 & 3 & 2 \\
\hline 1 & D & A & A & A & D & B \\
2 & A & A & A & A & A & \\
3 & A & C & A & B & & \\
4 & A & C & A & & & \\
5 & A & B & & & & \\
6 & A & & & & & \\
7 & & & & & & \\
\hline
\end{tabular}

\subsubsection{Reachability matrix}

The next step of the SSIM was to transform it into a binary matrix called the initial reachability matrix by substituting $\mathrm{A}, \mathrm{B}, \mathrm{C}$, and $\mathrm{D}$ by $1 \mathrm{~s}$ and $0 \mathrm{~s}$ (Tables 7, 8 and 9). The rules for the substitution of $1 \mathrm{~s}$ and $0 \mathrm{~s}$ are as follows:

- if the $(i, j)$ entry in the SSIM is A, then the $(i, j)$ entry in the reachability matrix becomes 1 and the (j,i) entry becomes 0 . 
Table 7 Initial reachability matrix for technology success factors

Table 8 Initial reachability matrix for human success factors

Table 9 Initial reachability matrix for organisational success factors

\begin{tabular}{lllllllllll}
\hline $\begin{array}{l}\text { Success } \\
\text { Factors }\end{array}$ & 10 & 9 & 8 & 7 & 6 & 5 & 4 & 3 & 2 & 1 \\
\hline 1 & 0 & 0 & 1 & 1 & 1 & 1 & 1 & 0 & 1 & 1 \\
2 & 0 & 0 & 1 & 0 & 0 & 0 & 0 & 0 & 1 & 1 \\
3 & 1 & 1 & 1 & 0 & 1 & 1 & 1 & 1 & 1 & 1 \\
4 & 1 & 1 & 0 & 0 & 0 & 0 & 1 & 0 & 1 & 0 \\
5 & 0 & 0 & 1 & 1 & 0 & 1 & 1 & 0 & 1 & 0 \\
6 & 1 & 1 & 1 & 0 & 1 & 1 & 0 & 0 & 1 & 0 \\
7 & 1 & 0 & 1 & 1 & 1 & 0 & 1 & 0 & 1 & 0 \\
8 & 1 & 1 & 1 & 0 & 0 & 0 & 1 & 0 & 0 & 0 \\
9 & 0 & 1 & 0 & 0 & 0 & 0 & 0 & 0 & 0 & 0 \\
10 & 1 & 0 & 0 & 0 & 0 & 0 & 0 & 0 & 0 & 0 \\
\hline
\end{tabular}

\begin{tabular}{llllllll}
\hline $\begin{array}{l}\text { Success Fac- } \\
\text { tors }\end{array}$ & 7 & 6 & 5 & 4 & 3 & 2 & 1 \\
\hline 1 & 0 & 0 & 0 & 0 & 1 & 1 & 1 \\
2 & 0 & 0 & 0 & 1 & 0 & 1 & 0 \\
3 & 0 & 1 & 1 & 0 & 1 & 1 & 1 \\
4 & 0 & 1 & 0 & 1 & 1 & 1 & 1 \\
5 & 1 & 1 & 1 & 1 & 0 & 1 & 1 \\
6 & 1 & 1 & 1 & 0 & 0 & 1 & 1 \\
7 & 1 & 0 & 1 & 1 & 0 & 1 & 1 \\
\hline
\end{tabular}

\begin{tabular}{llllllll}
\hline $\begin{array}{l}\text { Success Fac- } \\
\text { tors }\end{array}$ & 7 & 6 & 5 & 4 & 3 & 2 & 1 \\
\hline 1 & 0 & 1 & 1 & 1 & 0 & 0 & 1 \\
2 & 1 & 1 & 1 & 1 & 1 & 1 & 1 \\
3 & 1 & 1 & 1 & 0 & 1 & 0 & 0 \\
4 & 1 & 1 & 1 & 1 & 1 & 0 & 0 \\
5 & 1 & 0 & 1 & 0 & 0 & 0 & 0 \\
6 & 1 & 1 & 1 & 1 & 1 & 0 & 0 \\
7 & 1 & 0 & 0 & 0 & 0 & 0 & 0 \\
\hline
\end{tabular}

- if the $(i, j)$ entry in the SSIM is B, then the $(i, j)$ entry in the reachability matrix becomes 0 and the $(\mathrm{j}, \mathrm{i})$ entry becomes 1 .

- if the $(i, j)$ entry in the SSIM is C, then the $(i, j)$ entry in the reachability matrix becomes 1 and the $(\mathrm{j}, \mathrm{i})$ entry becomes 1 .

- if the $(i, j)$ entry in the SSIM is D, then the $(i, j)$ entry in the reachability matrix becomes 0 and the $(\mathrm{j}, \mathrm{i})$ entry becomes 0 . 
Table 10 Final reachability matrix for technology success factors

\begin{tabular}{llllllllllll}
\hline Success Factors & 10 & 9 & 8 & 7 & 6 & 5 & 4 & 3 & 2 & 1 & Driving Power \\
\hline 1 & $1^{*}$ & $1^{*}$ & 1 & 1 & 1 & 1 & 1 & 0 & 1 & 1 & 9 \\
2 & $1^{*}$ & $1^{*}$ & 1 & $1^{*}$ & $1^{*}$ & $1^{*}$ & $1^{*}$ & 0 & 1 & 1 & 9 \\
3 & 1 & 1 & 1 & $1^{*}$ & 1 & 1 & 1 & 1 & 1 & 1 & 10 \\
4 & 1 & 1 & $1^{*}$ & 0 & 0 & 0 & 1 & 0 & 1 & $1^{*}$ & 6 \\
5 & $1^{*}$ & $1^{*}$ & 1 & 1 & $1^{*}$ & 1 & 1 & 0 & 1 & $1^{*}$ & 9 \\
6 & 1 & 1 & 1 & $1^{*}$ & 1 & 1 & $1^{*}$ & 0 & 1 & $1^{*}$ & 9 \\
7 & 1 & $1^{*}$ & 1 & 1 & 1 & $1^{*}$ & 1 & 0 & 1 & $1^{*}$ & 9 \\
8 & 1 & 1 & 1 & 0 & 0 & 0 & 1 & 0 & $1^{*}$ & 0 & 5 \\
9 & 0 & 1 & 0 & 0 & 0 & 0 & 0 & 0 & 0 & 0 & 1 \\
10 & 1 & 0 & 0 & 0 & 0 & 0 & 0 & 0 & 0 & 0 & 1 \\
Dependence & 9 & 9 & 8 & 6 & 6 & 6 & 8 & 1 & 8 & 7 & \\
\hline
\end{tabular}

$1 *$ indicates the transitivity relationships

The final reachability matrix is obtained by incorporating the transitivities as enumerated in the ISM methodology (Tables 10, 11 and 12). It shows the driving power and dependence of each variable. The driving power of a success factor is defined as the total number of effecters (including itself), which may help to achieve. At the same time, dependence is the total number of success factors that are responsible for this effecter, which may help to achieve it. The variables driving power and dependencies will be analysed and classified into four categories of autonomous, dependent, linkage and independent (driver) variables, using a cross-impact matrix multiplication method (MICMAC) which is considered common best practice within the ISM methodology for classifying variables.

Table 11 Final reachability matrix for human success factors

\begin{tabular}{lllllllll}
\hline Success Factors & 7 & 6 & 5 & 4 & 3 & 2 & 1 & Driving Power \\
\hline 1 & 0 & $1 *$ & $1 *$ & $1 *$ & 1 & 1 & 1 & 6 \\
2 & 0 & $1 *$ & 0 & 1 & $1 *$ & 1 & $1 *$ & 5 \\
3 & $1 *$ & 1 & 1 & $1 *$ & 1 & 1 & 1 & 7 \\
4 & 0 & 1 & $1 *$ & 1 & 1 & 1 & 1 & 6 \\
5 & 1 & 1 & 1 & 1 & $1 *$ & 1 & 1 & 7 \\
6 & 1 & 1 & 1 & $1 *$ & $1 *$ & 1 & 1 & 7 \\
7 & 1 & $1 *$ & 1 & 1 & $1 *$ & 1 & 1 & 7 \\
Dependence & 4 & 7 & 6 & 7 & 7 & 7 & 7 &
\end{tabular}

$1 *$ indicates the transitivity relationships 
Table 12 Final reachability matrix for organisational success factors

\begin{tabular}{lllllllll}
\hline Success Factors & 7 & 6 & 5 & 4 & 3 & 2 & 1 & Driving Power \\
\hline 1 & $1^{*}$ & 1 & 1 & 1 & $1 *$ & 0 & 1 & 6 \\
2 & 1 & 1 & 1 & 1 & 1 & 1 & 1 & 7 \\
3 & 1 & 1 & 1 & $1 *$ & 1 & 0 & 0 & 5 \\
4 & 1 & 1 & 1 & 1 & 1 & 0 & 0 & 5 \\
5 & 1 & 0 & 1 & 0 & 0 & 0 & 0 & 2 \\
6 & 1 & 1 & 1 & 1 & 1 & 0 & 0 & 5 \\
7 & 1 & 0 & 0 & 0 & 0 & 0 & 0 & 1 \\
Dependence & 7 & 5 & 6 & 5 & 5 & 1 & 2 & \\
\hline
\end{tabular}

$1 *$ indicates the transitivity relationships

\subsubsection{Level partitioning}

The reachability and antecedent set for success factor variables are determined from the final reachability matrix. It includes comparing the reachability and antecedent sets of success factor variables and delineating levels on the basis of intersection sets. Then, the intersection of reachability and antecedent sets is derived for all success factors. The success factor for the reachability and intersection sets is the same as the top-level success factor in the ISM hierarchy.

The top-level success factor of the hierarchy would not help achieve any other success factor above its own level. When the top-level success factor is identified, it is separated out from the other success factors. After that, the same process finds the next level of success factor. This process continues until the levels of each success factor are found. These identified levels help in building the digraph and final model. The success factors along with their reachability set, antecedent set, intersection set and their respective levels are shown in terms of technology (Table 13), human (Table 14) and organisational (Table 15).

Table 13 Iteration for technology success factors showing all levels

\begin{tabular}{lllll}
\hline Success factor & Reach set & Antee Set & Inter set & Level \\
\hline 1 & $1,2,4,5,6,7,8,9,10$ & $1,2,3,4,5,6,7$ & $1,2,4,5,6,7$ & 4 \\
2 & $1,2,4,5,6,7,8,9,10$ & $1,2,3,4,5,6,7,8$ & $1,2,4,5,6,7,8$ & 4 \\
3 & $1,2,3,4,5,6,7,8,9,10$ & 3 & 3 & 5 \\
4 & $1,2,4,8,9,10$ & $1,2,3,4,5,6,7,8$ & $1,2,4,8$ & 3 \\
5 & $1,2,4,5,6,7,8,9,10$ & $1,2,3,5,6,7$ & $1,2,4,5,6,7$ & 4 \\
6 & $1,2,4,5,6,7,8,9,10$ & $1,2,3,5,6,7,8$ & $1,2,4,5,6,7,8$ & 4 \\
7 & $1,2,4,5,6,7,8,9,10$ & $1,2,3,5,6,7$ & $1,2,4,5,6,7$ & 4 \\
8 & $2,4,8,9,10$ & $1,2,3,4,5,6,7,8$ & $2,4,8$ & 2 \\
9 & 9 & $1,2,3,4,5,6,7,8,9$ & 9 & 1 \\
10 & 10 & $1,2,3,4,5,6,7,8,10$ & 10 & 1 \\
\hline
\end{tabular}


Table 14 Iteration for human success factors showing all levels

\begin{tabular}{lllll}
\hline Success factor & Reach set & Antee Set & Inter set & Level \\
\hline 1 & $1,2,3,4,5,6$ & $1,2,3,4,5,6,7$ & $1,2,3,4,5,6$ & 2 \\
2 & $1,2,3,4,6$ & $1,2,3,4,5,6,7$ & $1,2,3,4,6$ & 1 \\
3 & $1,2,3,4,5,6,7$ & $1,2,3,4,5,6,7$ & $1,2,3,4,5,6,7$ & 3 \\
4 & $1,2,3,4,5,6$ & $1,2,3,4,5,6,7$ & $1,2,3,4,5,6$ & 2 \\
5 & $1,2,3,4,5,6,7$ & $1,3,4,5,6,7$ & $1,3,4,5,6,7$ & 3 \\
6 & $1,2,3,4,5,6,7$ & $1,2,3,4,5,6,7$ & $1,2,3,4,5,6,7$ & 3 \\
7 & $1,2,3,4,5,6,7$ & $3,5,6,7$ & $3,5,6,7$ & 3 \\
\hline
\end{tabular}

Table 15 Iteration for organisational success factors showing all levels

\begin{tabular}{lllll}
\hline Success factor & Reach set & Antee Set & Inter set & Level \\
\hline 1 & $1,3,4,5,6,7$ & 1,2 & 1 & 4 \\
2 & $1,2,3,4,5,6,7$ & 2 & 2 & 5 \\
3 & $3,4,5,6,7$ & $1,2,3,4,6$ & $3,4,6$ & 3 \\
4 & $3,4,5,6,7$ & $1,2,3,4,6$ & $3,4,6$ & 3 \\
5 & 5,7 & $1,2,3,4,5,6$ & 5 & 2 \\
6 & $3,4,5,6,7$ & $1,2,3,4,6$ & $3,4,6$ & 3 \\
7 & 7 & $1,2,3,4,5,6,7$ & 7 & 1 \\
\hline
\end{tabular}

\subsubsection{Formation of ISM-based model}

The structural model of LMS diffusion in HEIs has been generated based on the final reachability matrix of each dimension (technology, human, and organisational), and the digraph is drawn. The transitivities are removed as described in ISM methodology.

In respect to the technology aspect (Fig. 1), it has been observed that 'clear policies for LMS implementation' is the fundamental effector that is driving all other technology success factors. That because this helps in setting a general plan of action used to guide desired outcomes as it form the basis of the ISM hierarchy. Several universities in KSA have chosen to introduce LMS to their institutions. Therefore, if they have a clear policy for LMS implementation, it will be the most powerful effector to drive other success factors (Alshammari et al., 2016; Alharbi \& Drew, 2014). Proper technology infrastructure', 'Availability of IT equipment', 'technical support', 'LMS based on the university's needs' and 'technical integration' are dependent on 'clear policies for LMS implementation'. These factors are much needed for a clear policy for the successful operation of LMS services, to help users perform academic activities and provide user-friendly assistance to LMS users. Moreover, the technical integration in educational activities within this context could consequently make teaching easy, increase users engagement, make collaboration effective as well as make information accessible. This results in providing educational process reengineering (EPR). EPR is necessary to help instructors and learners effectively function within educational activities as well 


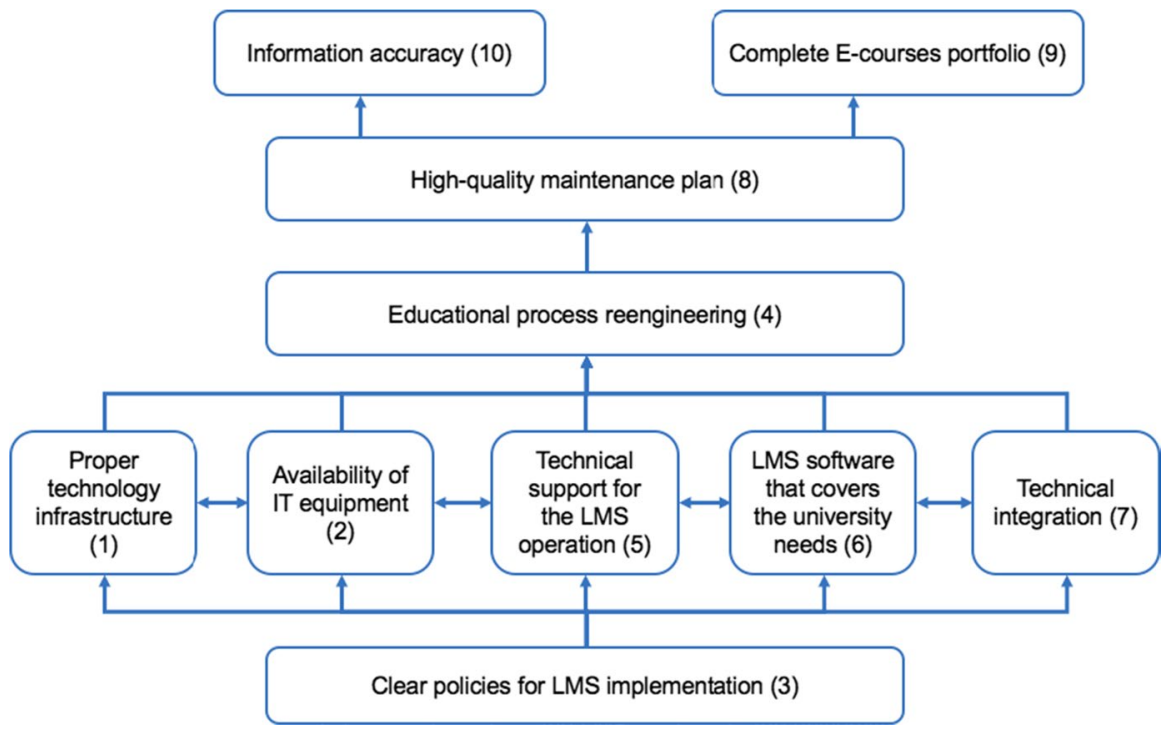

Fig. 1 ISM-based model for the technology success factors

as reduce classroom interruptions and discipline problems because they tell learners how things will work (Kituyi \& Tusubira, 2013). The maintenance plan is needed to enhance system reliability and availability as well as to avoid system failures or errors. The accurate information and complete e-courses portfolio are not driving effectors as they appear at the top of the hierarchy. They are a combination of the university's data from various sources to provide users with a unified view, which depicts the successful implementation of technology operations (Rajesh, 2016).

Regarding the human aspect (Fig. 2) the study found that; the strengthening and standardisation of IT education resources were required. It also found significant that, computer skills for IT staff and proper training of staff was necessary, in order to impart that knowledge to users and improve human competencies. These were very significant factors for succes in improving the LMS utilisation and wide spread implementation across the university. These factors were affecting each other. The link between these factors suggests that staff in Saudi universities need not only the necessary skills to handle and operate LMS but may also cooperate in introducing LMS in their institutions successfully. According to Asiri et al. (2012), proper training, high level of computer skills, and competencies play vital roles in the adoption of LMS in the HEIs. A comprehensive vision to focus on educational goals and to the delivery of necessary knowledge of LMS aspects for end-users are dependent on these factors. One of the significant benefits of a vision is that; it can be motivating and inspiring to ultimate users. When an individual understands and aligns with the organisation vision, they are able to readily commit to, and engage in, the organisation's efforts. That leads to the Implementation of the educational processes through LMS (Mayer, 2004; Zampunieris, 2006). Implementation of the educational processes through LMS should easily be facilitating educational activities, which often 


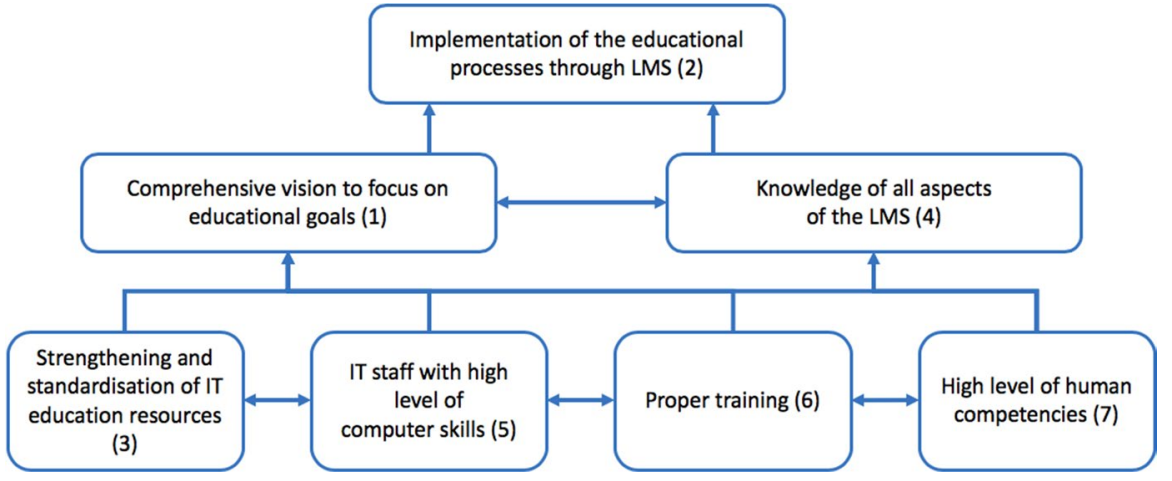

Fig. 2 ISM-based model for the human success factors

result in the successful implementation of human operations. This variable appears at the top of the hierarchy and is very important factor in development of learning opportunities and acceptance within organisation.

In respect to the organisational aspect (Fig. 3), it is indicated that top management support is a very significant factor for improving the organisational aspect of LMS as it forms the base of the ISM hierarchy. Saudi universities still need to top management support to improve LMS implementation within their institution. According to (Naveh et al., 2010), top management support leads to an increase in LMS usage and user satisfaction. It also helps the organisation's staff to understand users' characteristics and online needs to facilitate educational activities as each university may have different requirements. Necessary support to academics to produce digital content, a proper training for end users and increases the awareness level among academics and students are dependent on the university's requirement to facilitate educational activities. These factors lead to increasing the encouragement

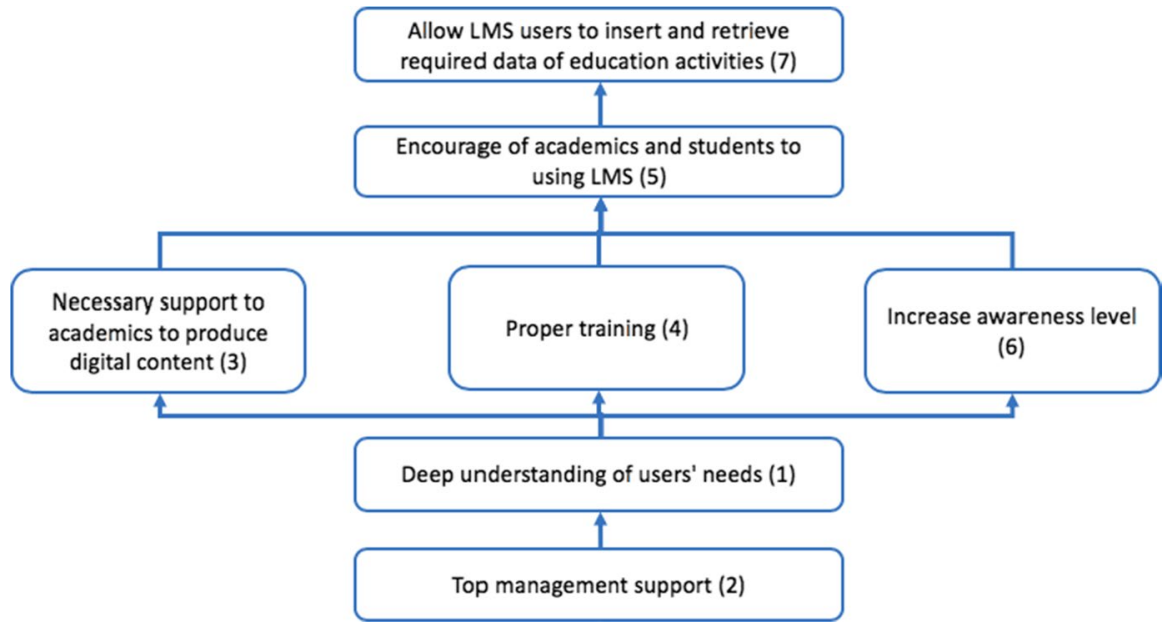

Fig. 3 ISM-based model for the organisational success factors 
of academics and students to use the LMS. This encouragement drives to allowing LMS users to insert and retrieve all required data of educational activities. Ozkan et al. (2009) suggest that necessary support to LMS users', proper training and awareness are important factors to increased users' attitude of LMS. Thus, the management of HEIs must address these factors more carefully in LMS implementation. These factors help to achieve the desired result variables and appear at the top of the ISM hierarchy for the organisation aspect.

\subsubsection{MICMAC analysis}

Success factors in terms of technology, human, and organisational aspects have been classified based on their driving and dependence power into four categories:

- Autonomous success factors.

- dependent success factors.

- linkage success factors.

- independent success factors.

This classification of success factors for the LMS diffusion are similar to the classification used by Mandal and Deshmukh (1994). In this analysis, the success factors in terms of technology, human, and organisation variables, as described earlier, are classified into four clusters (Figs. 4, 5 and 6).

Autonomous variables are represented in the first cluster and have weak driving power and dependence. The "dependent variables" represent the second cluster which have weak driving power but strong dependence. Whereas, "linkage variables", the third cluster, have strong driving power and strong dependence. The fourth cluster have strong driving power but weak dependence and are called "independent variables". Tables 10, 11, and 12 show the driving power and dependence of each success factor in terms of technology, human, and organisational aspects. The objective behind the classification of the success factors is to analyse the driver power and dependency of the success factors in terms of technology, human, and organisational aspects.

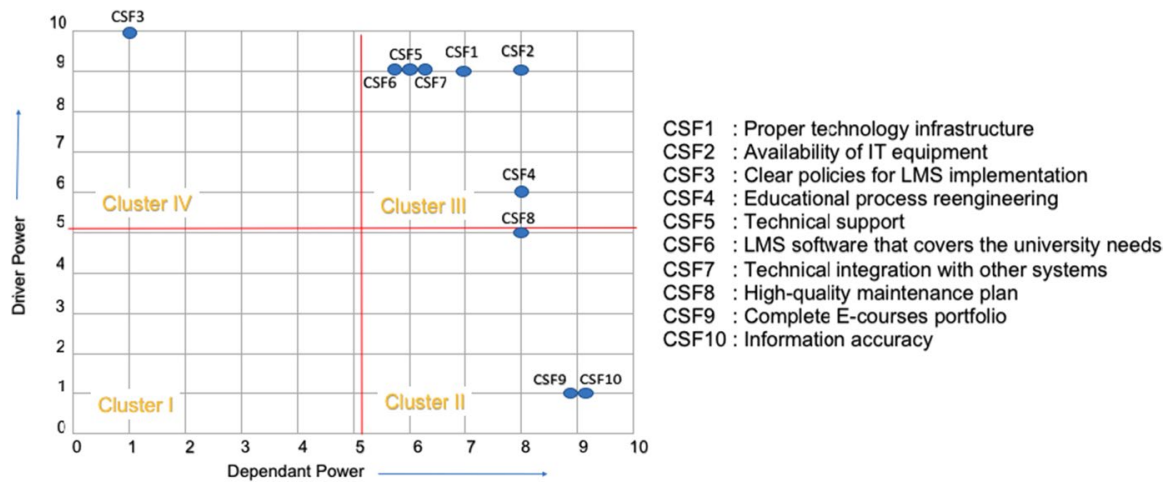

Fig. 4 Cluster of technology success factors 


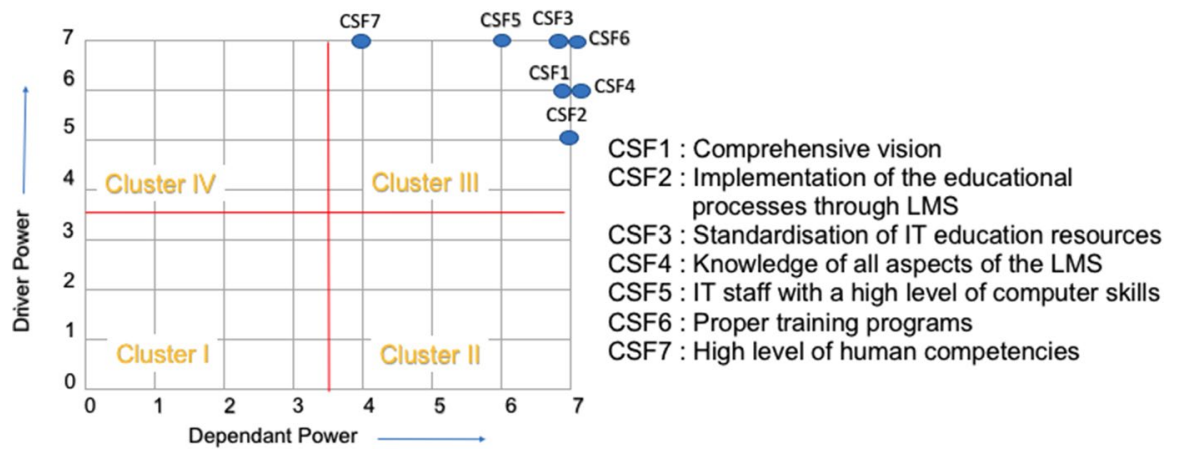

Fig. 5 Cluster of human success factors

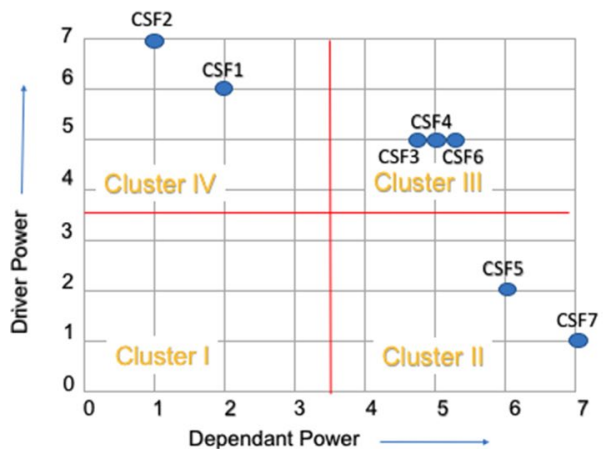

CSF1 : Deep understanding of users' needs

CSF2 : Top management support

CSF3 : Produce digital content

CSF4 : Proper training program for academics and students

CSF5 : Encourage of academics and students to using LMS

CSF6 : Increase awareness level for academics and students

CSF7 : knowledge sharing among LMS users

Fig. 6 Cluster of organisational success factors

\section{Discussion}

The findings reveal that there are specific requirements and needs for LMS in HEIs. The literature review culminates in the conclusion that the needs and requirements for LMS in HEIs can be summarised into technology, human and organisational factors. However, there is limited concurrence on which of these factors is of highest priority. Ayres et al. (2013) and (Gratz \& Looney, 2020) attribute the disparity in views to the differences in study settings and methodologies, as well as the dynamic nature of technology. The findings in this study relate to HEIs in the KSA.

One of the primary goals of successful LMS implementation is to facilitate learning processes, providing proper technology platform, responding to continuous improvement/update as well as an extension of LMS functions and services to the users of HEIs as per dynamic needs of all stakeholders under a particular HEI. Therefore, looking at all three aspects, e.g. technology, human and organisation, it is essential to address all connected, dependant and driving factors at the same time and with due strength. Otherwise, the ratio of successful information system projects would be noticeably low as in the case of KSA or other similar countries. This 
research identified the key success factors for LMS diffusion in HEIs using ISM methodology. This research identified the key success factors for LMS diffusion in HEIs using ISM methodology. The ISM approach has been used to scientifically identify the complex relationships among three categories of success factors for the LMS in terms of technology, human, and organisational aspects.

The findings relating to the technology aspect (Table 1, and Fig. 1) shows that proper technology infrastructure is necessary to operate and manage e-learning and clear policies for the implementation and extended use/support of LMS functions related to technology. Based on the gap analysis, the technology aspect revolves around information, technology and processes. Both instructors and learners must have access to the same technologies in the same time domain giving a need to continuous update of new services and monitoring of existing use of such technological services. The intersection between the access by the academics and learners is often overlooked in past studies. In the study, rather than being treated as separate entities, the instructors and learners are viewed as a monolith. This is in recognition of the fact that although there are differences in the technological abilities of the learners and instructors, for an LMS to function effectively, both parties have to have convergent objectives and interests. This is why in this study; the impact of technologyrelated factors is highlighted. The concerns surrounding technology infrastructure relate to the foundational elements that make it possible for the LMS technology to be identified, adopted and implemented successfully. These infrastructures, such as internet connectivity, availability of the right hardware and software components, the ability to understand the philosophy and technical aspects of technologies, play an integral role in creating the environment for the implementation of LMS. They also facilitate the conceptualisation of what LMSs do, to reduce the disparity between expectations and reality. These are very significant concepts for improving the technology aspect of LMS.

Similarly, data from human aspects shows that, strengthening and the standardisation of IT education resources, level of computer skills for IT staff, proper training programmes for staff to deliver knowledge to users as well as a high level of human competencies in use and management of LMS services are also very significant factors for improving the human aspect of LMS (Table 2, and Fig. 2). Past studies reveal that whereas technology has advanced significantly, the input of human factors is key to success (Ibrahim, 2018). The input of humans varies across different domains and all life cycles of the adoption and implementation. However, as indicated by Lwoga (2014) and Solangi et al. (2018), challenges with the skills and capabilities of the human resources within the HEIs can be solved through several strategic and tactical decisions. Starting with the use of outsourced resources, to the implementation of training and development packages to help the academics catch up on the use of LMS, these barriers can be solved in several ways. However, as indicated by Al-Fraihat et al. (2017), these outcomes are dependent on whether the technology is perceived as being useful to the instructors, based on whether it helps them achieve the goals of teaching.

The support of top management is again a very significant organisation success factor for improving the organisational aspect of LMS implementation across the departments and courses (Table 3, and Fig. 3). All these factors have high driving 
power and less dependence power. Therefore, these factors can be treated as key success factors for improving LMS diffusion in HEIs. They can also act as a guide for HEIs so that management may effectively deal with these factors and the management can decide an appropriate course of action for the successful implementation. Past studies have indicated that organisational support is an integral component of the successful adoption and implementation of any new technologies (Basak et al., 2016). The characteristics of the organisation are also integral in understanding the barriers and successes. This is because HEIs hold more and better resources as compared to lower institutions of learning. The characteristics of the learners and the academics, specifically their technical abilities in understanding basic and complex IT systems are often expected to be higher than within other learning institutions (Abdullah \& Ward, 2016). Consequently, the management teams are expected to have a better appreciation of what is required for LMS to be adopted and implemented. The results herein reveal that the challenges in acceptance of the technology can be attributed to the lack of preparedness for this form of technological change. Binyamin et al. (2017) reveal that within the Saudi context, most of the technologies adopted are easily assimilated, with particularly high levels of organisational support, since the government is committed to the creation of a knowledge economy, and the success in the educational sector.

This study has other implications for practicing managers. The following points summarise the managerial implications emerging from this study:

Technology implications:

- A high-quality maintenance plan for LMS, complete e-courses portfolio and information accuracy are weak drivers, yet are strongly dependent on other variables. The primary goal of an effective maintenance plan is avoiding delay. An effective maintenance plan is to improve productivity and work quality by anticipating and eliminating potential delays during educational activities. This can be supported with the analysis of technology success factors' result, which showed that desired performance of LMS can be attained by regularly performing both testing and maintenance procedures of LMS (Oludele et al., 2014). On the other hand, e-learning content and information accuracy together are the main factors that increase or decrease the efficiency of the e-learning system (Alla \& Faryadi, 2013).

- There are six technology success factors for LMS implementation, namely, 'proper technology infrastructure to operate and manage LMS', 'Availability of IT equipment that helps users perform academic activities', 'Educational process reengineering', 'technical support', 'LMS based on the university needs' and 'technical integration'. They are the linkage variables and have strong driver power as well as strong dependence. Thus, proper IT infrastructure enabling and facilitating process changes in contemporary HEIs. The technical teams work on installing, configuring, and updating hardware and software. They also work on fixing any issue related to the equipment that may come up on a daily basis. Additionally, the technical integration in educational activities within this con- 
text could consequently make educational activities easy for users. Therefore, HEIs should work together with technology providers to improve these factors to improve the performance of LMS implementation. This can be supported with findings of Solangi et al. (2018), Basak et al. (2016), Iqbal and Qureshi (2011), Mtebe (2015), Kraleva et al. (2019) and Abu-Shawar et al. (2006).

- The clear policies for LMS implementation were observed as having greater driving power. This means that almost all experts HEIs and technology providers were clear enough towards the importance of clear and specified policies so that proper technology infrastructures, IT equipment, technical support provisions, and needed LMS modules are well integrated through a set of specified procedures. They believe it may be discussed at length perhaps during the planning stage for efficient and integrated LMS and its functions as per HEIs objectives. Welle-Strand and Thune (2003), clear policies for LMS implementation expected to facilitate learning and to make it more efficient. This is very important that technology failures may be the least observable incidents. This can be justified by findings of Iqbal and Qureshi (2011) who showed that LMS policy is crucial for effective implementation of the learning management system because it governs how LMS can be developed, used, managed and administered. That idea is further supported by the next level of the ISM model, where; educational process reengineering, better maintenance plans and standard formats of courses are specified. The conversion of existing courses or development of new modules may then follow the patterns. This way success is more achievable and therefore, HEIs must consider flawless technology success factors implementation carefully in LMS implementation.

\subsection{Human implications}

The autonomous, dependant and driving human success factors (Fig. 5) are relatively disconnected from the system. As this study shows, there are no autonomous, dependant and driving human success factors in terms of LMS diffusion. This may be a cause of the low success of implementation in most organisations as human are difficult to uniformly work for success until an organisational top-level commitment and possible rewards are in place. The third cluster consists of linkage human success factors that have strong driving power and strong dependent power. In this study, all human success factors show as linkage variables.

Above discussion is further supported by results in Figs. 2 and 5. Figure 2 presented the ISM model of human success factors, therefore gives driving importance to four human success factors namely; 3,5,6 and 7th factors identified by this model for human factors of the ISM model. This can be supported with findings of Turnbull et al. (2019), Lwoga (2014), Solangi et al. (2018) and Ayub et al. (2010). As without these factors, the technology aspects would be meaningless and ineffective. Which may consequently result in low usage and ultimate failure of LMS implementation. 


\subsection{Organisational implications}

- The "dependent variables" represent the second cluster which have weak driving power but strong dependence. 'Allow LMS users to insert and retrieve required data of education activities' and 'Encourage academics and students to use LMS' are seen as dependent organisational success factors. Thus, to achieve effective education, HEIs should engage learners as active participants in their learning, which means giving learners opportunities that promote change in the learner's conception of knowledge, as well as helping HEIs to build meaningful learning relationships between instructors and learners. This can be supported with findings of Santiago et al. (2020) who showed that effectiveness of LMS is based on how far it engages learners, provides interesting learning, and allows them to seek self-development proactively.

- Three organisational success factors for LMS implementation are to "necessary support to academics to produce digital content", "proper training programme for users based on their needs", and "increase the awareness level for academics and students". These are the linkage variables and have strong driver power as well as strong dependence. This can be supported with findings of Santiago et al. (2020), Solangi et al. (2018) \& Juhary (2014). Thus, HEIs should provide proper digital content (in a standard technology format) to make learning processes more standard and easier to learn. This will lead to essentially needed collaboration between learners and instructors. Proper training and awareness are business necessities that help to develop instructors' and learners' skills to increase interaction with educational technologies.

- The fourth cluster of organisational success factors, such as "deep understanding of users' needs to facilitate education activities" and "top management support" are at the bottom of the organisational success factors model, but have strong driving power. This can be supported with findings of Basak et al. (2016) \& Phongphaew and Jiamsanguanwong (2018).

Further evidence of real-life validation of results comes from Fig. 3, the organisation aspect of ISM approach used. For all success in technology and human aspects, in real life is not possible without the top management support identified as driving success factor in Fig. 3. However, top support is useless in practice if top management does not understand the actual user needs. Interestingly, it may be different from institution to institution. Some faculty may have positive attitudes and may have tried and informally tested multiple technologies for teaching and learning purposes. Therefore, the management could find internal expert resources for both levels one and two in Fig. 3 and can lead to many successful examples in the institutions (Sangi, 2009). Similarly level three success factors (3,4 and 6) in Fig. 3 are good omens identified for preparation of any particular HEI to drive on the road to success.

ISM model, therefore, can be used by general institutions who have started to use or they are planning to use e-learning and LMS in their institutions. It gives them key information on driving and dependent variables in all three aspects; technology, human and organisation. They can use the model as a guideline and can compare 
to find any flaws in their planning. Success is what is required and is very difficult to achieve in most organisations. However, if complex relationships are worked out like illustrated in this example, it could help many to avoid mistakes in real-life situations. However, one has to be careful in selecting both experts and the use of this methodology for developing their own ISM as real-life situations may be different. For example, LMS which does not support all desired functions of instructor or learners may not have uniform good access or languages of instructions or subject matters differ from country to country or institution to institution. Some factors may not have explicit connectivity depending upon data obtained from the heterogenous experts.

\section{Conclusion}

The study aimed to identify and rank the key success factors for improving LMS diffusion in KSA HEIs. The identification of success factors reveals that adoption, implementation and utilisation of LMS in the HEIs can only be achieved within a particular set of inputs and processes. In this research, only ten technology success factors, seven human success factors, and seven organisational success factors were used to develop the ISM models; however, more success factors can be included using the ISM methodology to develop the relationship among them. The findings reveal that although top management support, clear policies for the implementation of LMS, strengthening and the standardisation of IT education resources, level of computer skills for IT staff, proper training programmes for staff to deliver knowledge to users, a high level of human competencies play a distinctive role in the success of LMS diffusion, the main source of success lies within the management will and actions. The implementation of LMS is affected by the change in the upstream levels of the value chain for LMS. For instance, the HEIs have to decide on the choice of which hardware and software components to acquire, to optimise the benefits and costs of such a system. This involves taking into account how much the institution expects to utilise the LMS in the learning and teaching processes, the interests of the students in using the LMS, as well as the abilities of the instructors to utilise the LMSs to their full potential. The results of this study are limited to HIs. Further, the ISM models were validated using experts' judgment approach. A total of ten experts were contacted and explained the study's theme and aims: four of whom were worked within HEIs, whereas others were worked within educational technology provider companies. Their comments, advice and recommendations were taken into consideration. The absence of data and published reports on the other KSA HEIs represented additional study limitations, as did the lack of research on facilitating effective LMS implementation, preventing comparisons between the results of other investigators.

The success factors for improving LMS diffusion are limited to HEIs. Moreover, this research explained all three categories of technology, human and organisational success factors for improving LMS diffusion in HEIs. One thing needs to be noted that there exists a relationship between these three categories. This can be supported 
with findings of Basak et al. (2016), who revealed that human factors affect LMS implementation in higher education, such that these factors are further associated with organisational and technological factors. However, this relation between three categories has not been studied or examined in this research. Therefore, future researches need to consider this association for gaining further valuable insight. Further, in this research, the relationship models among the identified success factors in terms of technology, human and organisational have not been statistically validated. However, it has been suggested that future research may be targeted to develop the initial model through ISM for success factors for improving LMS implementation and then testing it using Structural equation modeling (SEM).

Abbreviations HEIs: Higher educational institutes; LMS: Learning management systems; ISM: Interpretive structural modelling; KSA: Kingdom of Saudi Arabia; IT: Information technology; IS: Information systems; ITPOSMO: Design reality gap model; ICT: Information communication technology; SSIM: Structural self-interaction matrix; MICMAC: Matrice d'Impacts croises-multiplication appliqúe an classment (cross-impact matrix multiplication applied to classification); CSF: Critical success factor; SEM: Structural equation modelling; EPR: Educational Process Reengineering

Authors contributions YA analyzed the literature, performed the survey and analyzed the data. JP reviewed the work, interpreted the results and was a major contributor in writing the manuscript. KS designed and supervised the research, reviewed the manuscript and was a major contributor in writing the manuscript. All authors read and approved the final manuscript.

Data availability The authors confirm that the data supporting the findings of this study are available within the article.

\section{Declarations}

Competing interests The authors declare that they have no competing interests.

Open Access This article is licensed under a Creative Commons Attribution 4.0 International License, which permits use, sharing, adaptation, distribution and reproduction in any medium or format, as long as you give appropriate credit to the original author(s) and the source, provide a link to the Creative Commons licence, and indicate if changes were made. The images or other third party material in this article are included in the article's Creative Commons licence, unless indicated otherwise in a credit line to the material. If material is not included in the article's Creative Commons licence and your intended use is not permitted by statutory regulation or exceeds the permitted use, you will need to obtain permission directly from the copyright holder. To view a copy of this licence, visit http://creativecommons.org/licen ses/by/4.0/.

\section{References}

Abdullah, F. \& Ward, R. (2016) Developing a General Extended Technology Acceptance Model for E-Learning (GETAMEL) by analysing commonly used external factors. Computers in Human Behavior, 56, 238-256. https://doi.org/10.1016/j.chb.2015.11.036.

Abu-shawar, B., Al-sadi, J., \& Hourani, A. (2006). Integrating the Learning Management System with other Online Administrative Systems at AOU. In Proceedings of The International Conference on Algorithmic Mathematics and Computer Science (AMCS'06) (pp. 22-25). 
Alebaikan, R., \& Troudi, S. (2010). Blended learning in Saudi universities: Challenges and perspectives. ALT-J, 18(1), 49-59. https://doi.org/10.1080/09687761003657614.

Al-Emran, M., Elsherif, H. M., \& Shaalan, K. (2016). Investigating attitudes towards the use of mobile learning in higher education. Computers in Human Behavior, 56, 93-102. https://doi.org/10.1016/j.chb.2015.11. 033.

Al-Fahad, F. N. (2010). The learners' satisfaction toward online e-learning implemented in the College of Applied Studies and Community Service, King Saud University, Saudi Arabia: Can e-learning replace the conventional system of education? Turkish Online Journal of Distance Education-TOJDE, 1(April), 238-246. https://doi.org/10.17718/tojde.13198.

Al-Fraihat, D., Joy, M., \& Sinclair, J. (2017). Identifying success factors for e-learning in higher education. In Proceedings of the International Conference on e-Learning, ICEL.

Alharbi, S., \& Drew, S. (2014). Using the technology acceptance model in understanding academics' Behavioural intention to use learning management systems. International Journal of Advanced Computer Science and Applications, 5(1), 143-155. https://doi.org/10.14569/IJACSA.2014.050120.

Alla, M. M. S. O., \& Faryadi, Q. (2013). The Effect of Information Quality in E-Learning System. International Journal of Applied Science and Technology, 3(6), 24-33.

Al-Nefaie, S. (2016). Investigating factors influencing students' attitude and performance when using webenhanced learning in developing countries : The case of Saudi Arabia. Phd Thesis, Department of Information Systems and Computing, Brunel University, London, United Kingd.

Alshammari, S. H., Ali, M. B. \& Rosli, M. S. (2016) The influences of technical support, self efficacy and instructional design on the usage and acceptance of LMS: A comprehensive review. Turkish Online Journal of Educational Technology, 15(2), 116-125.

Asiri, M. J., Mahmud, R. B., Abu Bakar, K., Mohd, A., \& Bin, A. F. (2012). Factors influencing the use of learning management system in Saudi Arabian higher education: A theoretical framework. Higher Education Studies, 2(2), 125-137. https://doi.org/10.5539/hes.v2n2p125.

Attri, R., Dev, N., \& Sharma, V. (2013). Interpretive structural Modelling ( ISM ) approach : An overview. Research Journal of Management Sciences, 2(2), 3-8.

Ayres, K. M., Mechling, L. \& Sansosti, F. J. (2013) The use of mobile technologies to assist with life skills/ independence of students with moderate/severe intellectual disability and/or autism spectrum disorders: Considerations for the future of school psychology. Psychology in the Schools, 50(3), 259-271. https://doi. org/10.1002/pits.21673.

Ayub, A. F. M., Tarmizi, R. A., Jaafar, W. M. W., Ali, W. Z. W., \& Luan, W. S. (2010). Factors Influencing Students ' Use a Learning Management System Portal : Perspective from Higher Education Students. International Journal of Education and Information Technologies, 4(2), 100-108.

Basak, S. K., Wotto, M., \& Bélanger, P. (2016). A Framework on the Critical Success Factors of E-Learning Implementation in Higher Education: A Review of the Literature. World Academy of Science, Engineering and Technology, International Journal of Social, Behavioral, Educational, Economic, Business and Industrial Engineering, 10(7), 2409-2414.

Binyamin, S., Rutter, M. \& Smith, S. (2017) The students' acceptance of learning management systems in Saudi Arabia: A case study of King Abdulaziz University. In: INTED2017 Proceedings, pp. 9324-9333. https:// doi.org/10.21125/inted.2017.2205.

Bora, J., \& Ahmed, M. (2013). E-learning using cloud computing. International Journal of Science and Modern Engineering, 1(2), 9-12.

Cavus, N. (2013). Selecting a learning management system (LMS) in developing countries: Instructors' evaluation. Interactive Learning Environments, 21(5), 419-437. https://doi.org/10.1080/10494820.2011.584321.

Giudice, M. Del, Rosaria, M., Peruta, D., \& Carayannis, E. G. (2014). Innovation, Human Capital and Trade Competitiveness. (M. A. Weresa, Ed.). Springer International Publishing. https://doi.org/10.1007/ 978-3-319-02072-3.

Edda, L. (2012). Making learning and web 2.0 technologies work for higher learning institutions in Africa. Campus-Wide Information Systems, 29(2), 90-107. https://doi.org/10.1108/10650741211212359.

Gautreau, C. (2011). Motivational factors affecting the integration of a learning management system by faculty. The Journal of Educators Online, 8(1), 1-25. https://doi.org/10.9743/JEO.2011.1.2.

Goffe, W. L., \& Sosin, K. (2005). Teaching with technology: May you live in interesting times. Journal of Economic Education, 36(3), 278-291. https://doi.org/10.3200/JECE.36.3.278-291.

Govindasamy, T. (2001). Successful implementation of e-learning pedagogical considerations. Internet and Higher Education. https://doi.org/10.1016/S1096-7516(01)00071-9. 
Gratz, E. \& Looney, L. (2020) Faculty resistance to change: An examination of motivators and barriers to teaching online in higher education. International Journal of Online Pedagogy and Course Design, 10(1), 1-14. https://doi.org/10.4018/IJOPCD.2020010101.

Heeks, R. (2003). Most eGovernment-for-Development Projects Fail: How Can Risks be Reduced? iGovernment Working Paper Series. https://doi.org/10.1017/CBO9781107415324.004.

Ibrahim, T. A. (2018) 'The Role of Technology Acceptance Model in Explaining University Academics' Acceptance and Behavioural Intention to Use Technology in Education. KnE Social Sciences, 3(6), 1162. https://doi.org/10.18502/kss.v3i6.2443.

Iqbal, S., \& Qureshi, I. A. (2011). Learning management systems (LMS): Inside matters. Information Management and Business Review, 3(4), 206-216. https://doi.org/10.16194/j.cnki.31-1059/g4.2011.07.016.

Jamal, H., \& Shanaah, A. (2011). The Role of Learning Management Systems in Educational Environments : An Exploratory Case Study, Master dissertation, school of Computer Science, Phisics and Mathematics, Linnaeus University, Växjö campus, Sweden. Retrieved from http://www.diva-portal.org/smash/get/diva2: 435519/FULLTEXT01.pdf. Accessed 27 Dec 2020.

Jharkharia, S., \& Shankar, R. (2005). IT-enablement of supply chains: Understanding the barriers. Journal of Enterprise Information Management, 18(1), 11-27. https://doi.org/10.1108/17410390510571466.

Juhary, J. (2014). Perceived usefulness and ease of use of the learning management system as a learning tool. International Education Studies, 7(8), 23-34. https://doi.org/10.5539/ies.v7n8p23.

Kats, Y. (2013). Learning management systems and instructional design: best practices in online education. IGI Global.

Kefalas, P., Retalis, S., Stamatis, D., \& Kargidis, T. (2003). Quality assurance procedures and e-ODL. In International Conference on Networked Universities and e-Learning (pp. 8-9).

Khalid, M. S., Hossain, M. S., \& Rongbutsri, N. (2011). Educational Process Reengineering and diffusion of innovations in formal learning environment. In Proceedings of the 19th International Conference on Computers in Education, ICCE 2011.

Kituyi, G. \& Tusubira, I. (2013) A framework for the integration of e-learning in higher education institutions in developing countries. International Journal of Education and Development using Information and Communication Technology (IJEDICT), 9(2), 19-36.

Kraleva, R., Sabani, M., \& Kralev, V. (2019). An analysis of some learning management systems. International Journal on Advanced Science, Engineering and Information Technology. https://doi.org/10.18517/ijaseit.9. 4.9437.

Lwoga, E. (2014). Critical success factors for adoption of web-based learning management systems in Tanzania. International Journal of Education and Development Using Information and Communication Technology (IJEDICT).

Mandal, A., \& Deshmukh, S. G. (1994). Vendor selection using interpretive structural Modelling (ISM). International Journal of Operations \& Production Management, 14(6), 52-59. https://doi.org/10.1108/01443 579410062086.

Mayer, R. E. (2004). Should there be a three-strikes rule against pure discovery learning? American Psychologist, 59(1), 14-19. https://doi.org/10.1037/0003-066X.59.1.14.

Mtebe, J. S. (2015). Learning management system success: Increasing learning management system usage in higher education in sub-Saharan Africa. International Journal of Education and Development Using ICT, 11(2), 51-64.

Naveh, G., Tubin, D., \& Pliskin, N. (2010). Student LMS use and satisfaction in academic institutions: The organizational perspective. Internet and Higher Education, 13(3), 127-133. https://doi.org/10.1016/j.iheduc.2010.02.004.

Ohliati, J., \& Abbas, B. S. (2019). Measuring students satisfaction in using learning management system. International Journal of Emerging Technologies in Learning. https://doi.org/10.3991/ijet.v14.i04.9427.

Oludele, A., Ernest, O. E., Ifetayo, A. A., David, B. M., \& Chinazom, C. K. (2014). The design and implementation of a learning management system. International Journal of Advance Research, IJOAR .ORG, 2(11), 1-17.

Ozkan, S., Koseler, R., \& Baykal, N. (2009). Evaluating learning management systems: Adoption of hexagonal e-learning assessment model in higher education. Transforming Government: People, Process and Policy, 3(2), 111-130. https://doi.org/10.1108/17506160910960522.

Phongphaew, N., \& Jiamsanguanwong, A. (2018). Usability evaluation on learning management system. In Advances in Intelligent Systems and Computing (Vol. 607, pp. 39-48). https://doi.org/10.1007/ 978-3-319-60492-3_4.

Pocatilu, P., Alecu, F., \& Vetrici, M. (2009). Using Cloud Computing for E-learning Systems. In Proceedings of the 8th WSEAS International Conference on Data Networks, Communications, Computers, DNCOCO '09. 
Pyla, A. (2012). ICT as a Change Agent for Higher Education and Society. In Proceedings published by International Journal of Computer Applications IJCA (Vol. 1, pp. 25-30).

Queirós, R., Oliveira, L., Leal, J. P., \& Moreira, F. (2011). Integration of ePortfolios in learning management systems. In Lecture Notes in Computer Science (including subseries Lecture Notes in Artificial Intelligence and Lecture Notes in Bioinformatics). https://doi.org/10.1007/978-3-642-21934-4_40.

Radif, M. (2016). A Learning Management System Adoption Framework for Higher Education: The Case of Iraq, Ph.D.dissertation, School of Aerospace, Transport and Manufacturing, Cranfield University, Cranfield, Uinted Kingdom.

Rajesh, M. (2016). Traditional courses into online moving strategy. The Online Journal of Distance Education and E-Learning, 4(4), 19-63. Retrieved from http://tojdel.net/volume/tojdel-volume03-i03.pdf\#page=40. Accessed 27 Dec 2020.

Sangi, N. A. (2009). Access strategy for blended E-learning: An AIOU Case Study. Journal of the Research Center for Education Technology, 5(1), 96. Retrieved from http://www.rcetj.org/index.php/rcetj/article/ view/23/30. Accessed 27 Dec 2020.

Santiago, B. J., Ramírez, J. M. O., Rodríguez-Reséndiz, J., Dector, A., García, R. G., González-Durán, J. E. E., \& Sánchez, F. F. (2020). Learning management system-based evaluation to determine academic efficiency performance. Sustainability (Switzerland). https://doi.org/10.3390/su12104256.

Solangi, Z. A., Al Shahrani, F., \& Pandhiani, S. M. (2018). Factors affecting successful implementation of elearning: Study of colleges and institutes sector RCJ Saudi Arabia. International Journal of Emerging Technologies in Learning. https://doi.org/10.3991/ijet.v13i06.8537.

Turnbull, D., Chugh, R., \& Luck, J. (2019). Learning Management Systems: An Overview. In Encyclopedia of Education and Information Technologies. https://doi.org/10.1007/978-3-319-60013-0_248-1.

Welle-Strand, A., \& Thune, T. (2003). E-learning policies, practices and challenges in two Norwegian organizations. Evaluation and Program Planning. https://doi.org/10.1016/S0149-7189(03)00006-5.

Whelan, R., \& Bhartu, D. (2007). Factors in the deployment of a learning management system at the university of the south pacific. In Proceedings Ascilite Singapore (pp. 1053-1062).

Wingo, N. P., Ivankova, N. V., \& Moss, J. A. (2017). Faculty perceptions about teaching online: Exploring the literature using the technology acceptance model as an organizing framework. Online Learning, 21(1), 15-35. https://doi.org/10.24059/olj.v21i1.761.

Zampunieris, D. (2006). Implementation of a proactive learning management system. In E-Learn World Conference on E-Learning in Corporate, Government, Healthcare and Higher Education. Association for the Advancement of Computing in Education (AACE). (pp. 3145-3151).

Publisher's note Springer Nature remains neutral with regard to jurisdictional claims in published maps and institutional affiliations.

\section{Authors and Affiliations}

\section{Yousef Alduraywish $^{1} \cdot$ John Patsavellas ${ }^{1} \cdot$ Konstantinos Salonitis $^{1}{ }^{1}$}

Yousef Alduraywish

Y.Alduraywish@cranfield.ac.uk

John Patsavellas

John.Patsavellas@cranfield.ac.uk

Konstantinos Salonitis

k.salonitis@cranfield.ac.uk

1 School of Aerospace, Transport and Manufacturing, Cranfield University, Cranfield MK43 0AL, UK 